\title{
Глава 3
}

\section{МЕХАНИЗМЫ ИЗМЕНЕНИЯ ДИНАМИЧЕСКОЙ СЛОЖНОСТИ ПАТТЕРНОВ ЭЭГ, ЛЕЖАЩИЕ В ОСНОВЕ КОРРЕКЦИИ ПСИХОГЕННОЙ БОЛИ ПРИ ТРЕВОЖНО-ФОБИЧЕСКИХ СОСТОЯНИЯХ}

\section{1. Нелинейная динамика паттернов ЭЭГ человека при нарушении функционального состояния мозга, связанного с тревожно-фобическими расстройствами}

В настоящее время из-за эмоциональных и информационных перегрузок отмечается рост невротических заболеваний, среди которых практически в половине случаев встречаются тревожно-фобические расстройства [109]. Характерными симптомами при таких расстройствах являются повышенная тревожность, нарушение сна, различные фобии и психогенная боль (жалобы на абдоминальные, вертеброгенные и головные боли, не подтверждаемые медицинскими исследованиями).

Известно, что боль психогенной природы сопровождается нарушением функционального состояния мозга, которое проявляется в нарушении связей между корой и подкорковыми структурами на различных уровнях (таламическом, гипоталамическом или стволовом) [110]. При этом клиницисты отмечают трудности в фармакотерапии таких нарушений [111]. Поэтому наряду с разработкой новых безопасных лекарственных препаратов в настоящее время актуальной является разработка психотерапевтических методик по преодолению болевых симптомов. В работах $[112,113]$ отмечена положительная роль психорелаксационной методики для снятия боли. Одна из таких методик разработана В.А.Ишиновой в Научно-практическом центре реабилитации им. Г.А.Альбрехта $[112,114]$ и применялась автором методики в настоящей работе.

По этой методике человека просили принять удобное для него положение (сидя или лежа с закрытыми глазами) и сосредоточиться на местах локали- 
зации боли. При этом болевые ощущения по ассоциативным системам конвергировались в цветовое отражение, возникающее в головном мозге при закрытых глазах [112]. На протяжении сеанса психорелаксации длительностью 20 мин пациенты оценивали изменения интенсивности боли и отслеживали сопутствующую этим изменениям трансформацию цветовых пятен от цветов длинноволновой части спектра к цветам средне- и коротковолновой. Для каждого пациента проводилось от 10 до 20 сеансов. У некоторых пациентов снятие боли происходило уже к двадцатой минуте третьего сеанса, а другим требовалось значительно большее количество сеансов. У здоровых лиц боль вызывалась путем тактильного воздействия на срединную точку между большим и указательным пальцами в течение 10 мин. Исчезновение тактильного болевого ощущения происходило в среднем в течение 3 мин.

Для пациентов с тревожно-фобическими расстройствами ЭЭГ регистрировалась в состоянии ощущения психогенной боли и в состоянии психорелаксации. Данные для контрольной группы здоровых лиц содержали записи в трех состояниях: до болевой стимуляции, во время болевого воздействия и во время релаксации.

Поскольку нарушения функционального состояния мозга, связанные с тревожно-фобическими расстройствами, сопровождаются нарушением структуры паттернов ЭЭГ [110], методы анализа нелинейной динамики паттернов ЭЭГ в процессе психорелаксации позволяют оценить количественные изменения, происходящие в паттернах ЭЭГ при успешной психорелаксации, приводящей к нормализации функционального состояния мозга. С целью оценки эффективности психотерапевтического воздействия для снятия болевого синдрома у пациентов с тревожно-фобическими расстройствами были применены методы спектрального, вейвлетного и мультифрактального анализов фрагментов ЭЭГ в различных функциональных состояниях (во время ощущения пациентами психогенной боли и во время ее снятия с помощью психорелаксационной методики) $[105,115,116]$.

\section{2. Спектры Фурье паттернов ЭЭГ человека при тревожно-фобических расстройствах}

В серии тестов с применением психорелаксационной методики у здоровых лиц сегменты ЭЭГ в трех состояниях (до болевой стимуляции, во время стимуляции и во время психорелаксации) практически не отличались по спектрам мощности, доминировал альфа-ритм. В состоянии концентрации внимания на болевом ощущении все здоровые лица отмечали ахроматические цвета (черный или серый), а в состоянии психорелаксации - голубой цвет, относящийся к коротковолновой части спектра. Параллельно происходило исчезновение тактильного ощущения боли. Это совпадало с ранее полученными данными, в которых показано, что цветовые образы отражают болевую 
Во время психогенной боли
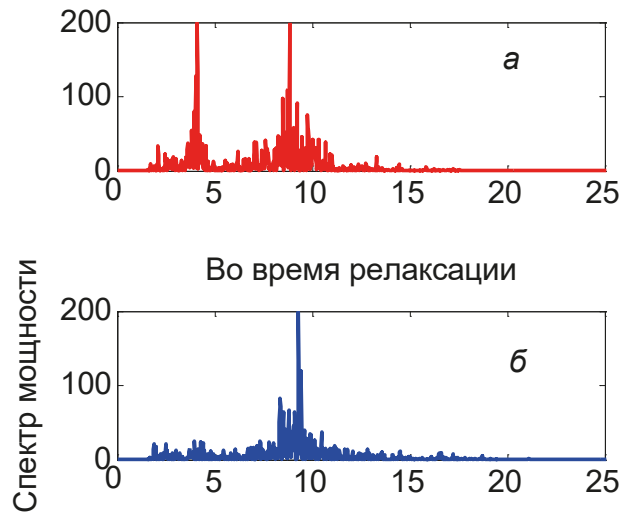

Во время релаксации

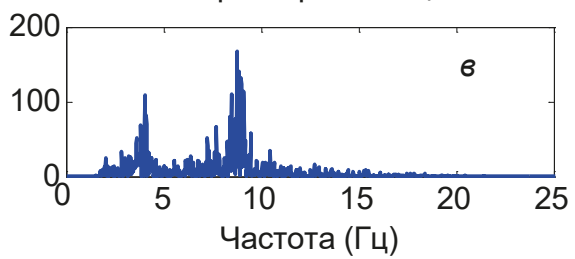

Во время психогенной боли

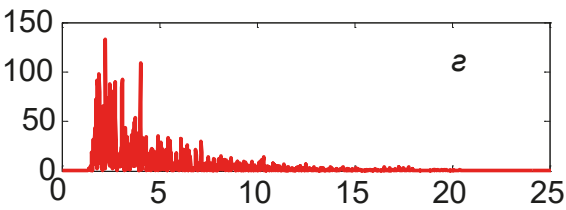

Во время релаксации

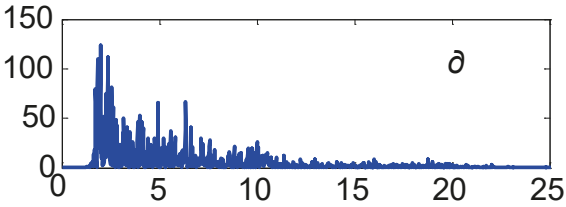

Во время релаксации

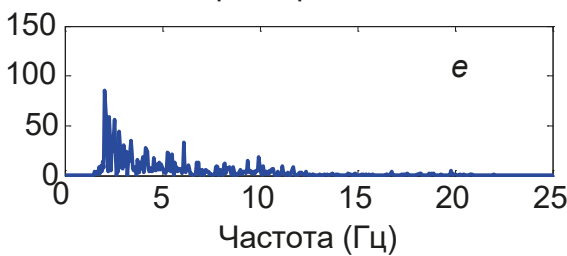

Puc. 3.1. Спектры мощности ЭЭГ человека с тревожно-фобическими расстройствами:

a, 6, в- из первой группы; $2, \partial, e-$ из второй группы

симптоматику и наличие психоэмоционального напряжения $[117,118]$. Ранее в работах $[112,114]$ было выявлено, что психотерапевтическое воздействие, снижающее это напряжение, сопровождается достоверным увеличением восприятия цветов коротковолновой части спектра.

Пациенты с тревожно-фобическими расстройствами были распределены на основании спектров мощности ЭЭГ по двум группам. В ЭЭГ пациентов первой группы при болевом ощущении в спектрах мощности на фоне хорошо выраженного альфа-ритма, отражающего оптимальные корково-подкорковые взаимоотношения [119], регистрировалась тета-активность (рис. 3.1, a), свидетельствующая о повышении неустойчивости нейродинамических процессов мозга [120]. Во время психорелаксации уровень тета-активности в затылочных отведениях падал у 45 \% пациентов группы (рис. 3.1, б), а у 55 \% - тета-активность сохранялась как в лобных, так и в затылочных отведениях (рис. 3.1, в). При этом улучшение психологического состояния не всегда коррелировало с уменьшением тета-активности. Иными словами, значимых изменений в улучшении психологического состояния по спектральному анализу ЭЭГ выявлено не было. Полное устранение болевого ощущения наблюдалось только у лиц, у которых цветовые пятна трансформировались в голубой цвет (61 \% пациентов первой группы). У $39 \%$ больных этой группы во время концентрации 
на болевом ощущении наблюдались преимущественно хроматические цвета длинноволновой части спектра (красный, желтый), и эти цвета сохранялись во время психорелаксации.

Во всех спектрах ЭЭГ второй группы пациентов наблюдалось значительное подавление альфа-составляющей ЭЭГ вплоть до полного ее исчезновения и появление низкоамплитудных нерегулярных тета-волн. Таким образом, для пациентов второй группы тета-активность преобладала во всех состояниях (рис. 3.1, 2, д, е). Это сопровождалось еще большей неустойчивостью нейродинамических процессов, повышением процессов возбуждения и усилением психоэмоционального напряжения. При психорелаксации трансформация ахроматических темных цветовых пятен не наблюдалась для 81 \% пациентов второй группы. У $19 \%$ пациентов ахроматические темные цвета изменялись на длинноволновые красный или оранжевый. Оба случая не были характерны для здоровых лиц и сопровождались отсутствием улучшения психофизиологического состояния пациента.

\section{3. Вейвлетные спектры паттернов ЭЭГ человека при тревожно-фобических расстройствах}

На основании вейвлетного анализа были оценены энергетические характеристики паттернов ЭЭГ до, во время и после психотерапевтического воздействия. Примеры распределений энергии $\left|W\left(a, t_{0}\right)\right|^{2}$ и глобальных вейвлетных спектров фрагментов ЭЭГ здорового человека приведены на рис. 3.2.

Во время болевого воздействия максимум глобального спектра $E_{\max }$ возрастает практически в три раза $\left(E_{\max }=6,9 \times 10^{4}\right.$ вместо $\left.E_{\max }=1,95 \times 10^{4}\right)$, а во время релаксации снижается до значения $E_{\max }=4 \times 10^{4}$, оставаясь в пределах одного и того же частотного.

При ощущении психогенной боли пациент из первой группы с тревожно-фобическими расстройствами в глобальном вейвлетом спектре наблюдал два максимума на частотах альфа- и тета-диапазонов $\left(E_{\max }=4 \times 10^{5}\right.$ и $\left.E_{\max }=5,1 \times 10^{5}\right)($ рис. 3.3$)$.

Во время релаксации у пациента $A$ из первой группы значение максимума глобальной энергии на частоте альфа-диапазона уменьшалось до величины $E_{\max }=4,2 \times 10^{4}$, а у пациента $B-$ до величины $E_{\max }=0,95 \times 10^{4}$. Значение максимума энергии на частоте тета-диапазона уменьшалось до величин $E_{\max }=1,5 \times 10^{4}$ и $E_{\max }=0,5 \times 10^{4}$ (см. рис. 3.3 ).

У $45 \%$ пациентов первой группы глобальная энергия в затылочных отведениях во время релаксации уменьшалась в десятки раз, и тета-активность заметно снижалась, а у 55 \% пациентов этой группы, несмотря на большее снижение глобальной энергии, тета-активность сохранялась. Улучшение психологического состояния не всегда коррелировало с уменьшением глобальной энергии, поэтому значимых изменений в улучшении психологического состо- 


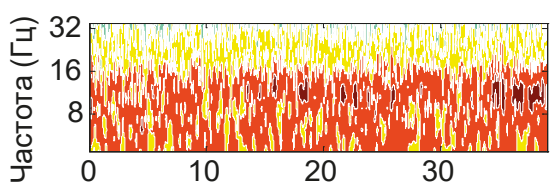

До болевого воздействия
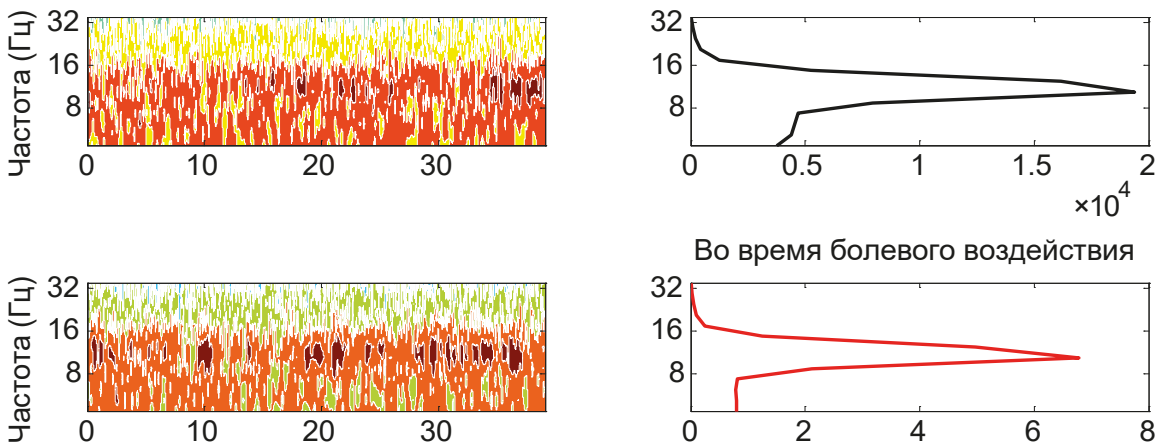

Во время болевого воздействия
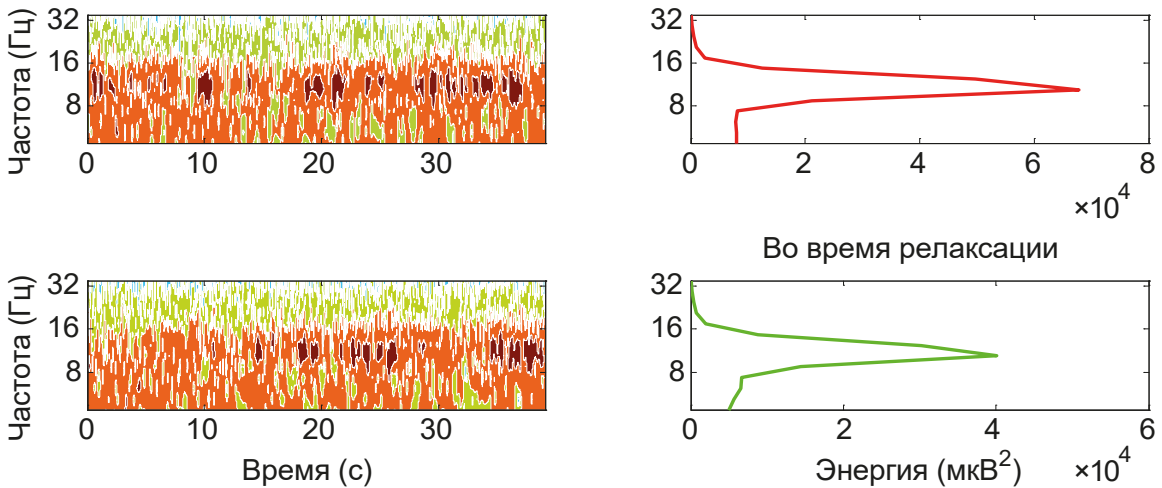

Во время релаксации

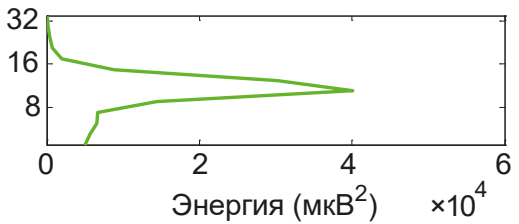

Puc. 3.2. Примеры распределений энергии $\left|W\left(a, t_{0}\right)\right|^{2}$ и глобальных вейвлетных спектров фрагментов ЭЭГ в различных состояниях здорового человека (отведение Qz)
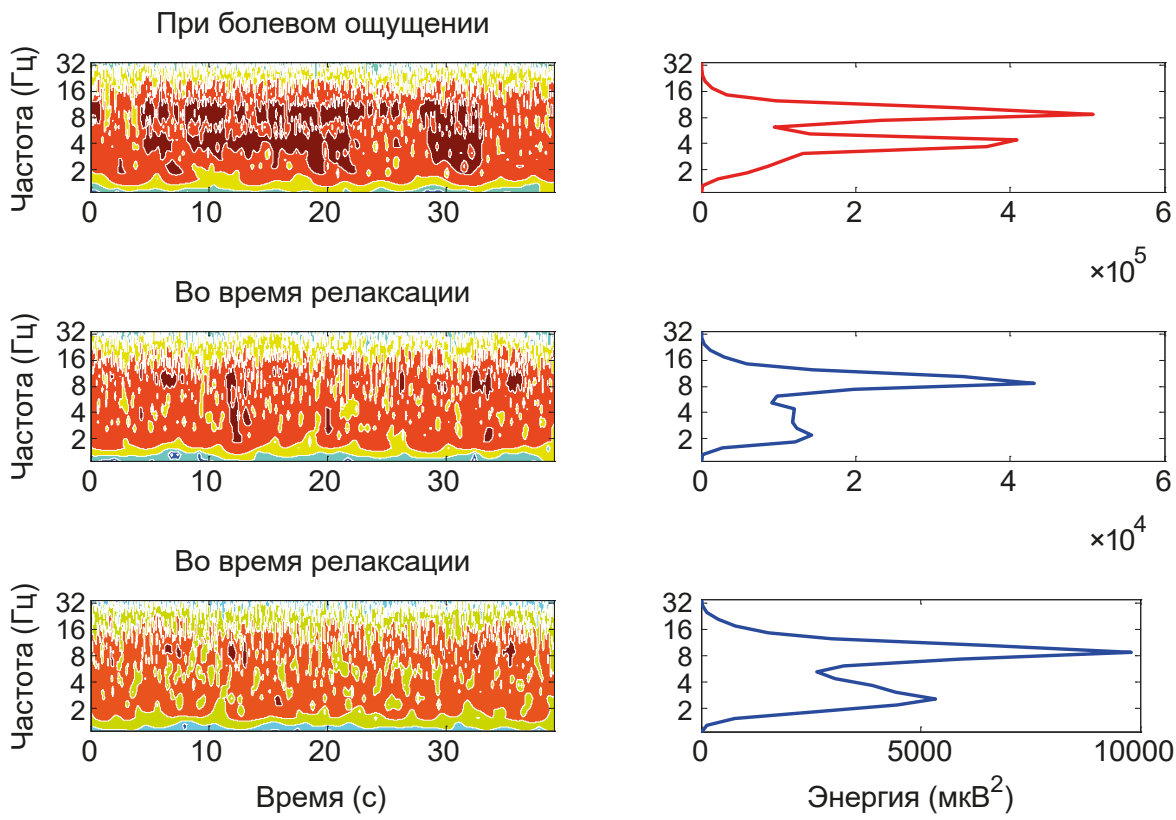

Puc. 3.3. Примеры распределений энергии $\left|W\left(a, t_{0}\right)\right|^{2}$ и глобальных вейвлетных спектров фрагментов ЭЭГ в различных состояниях человека с тревожно-фобическими расстройствами из первой группы (отведение Qz) 

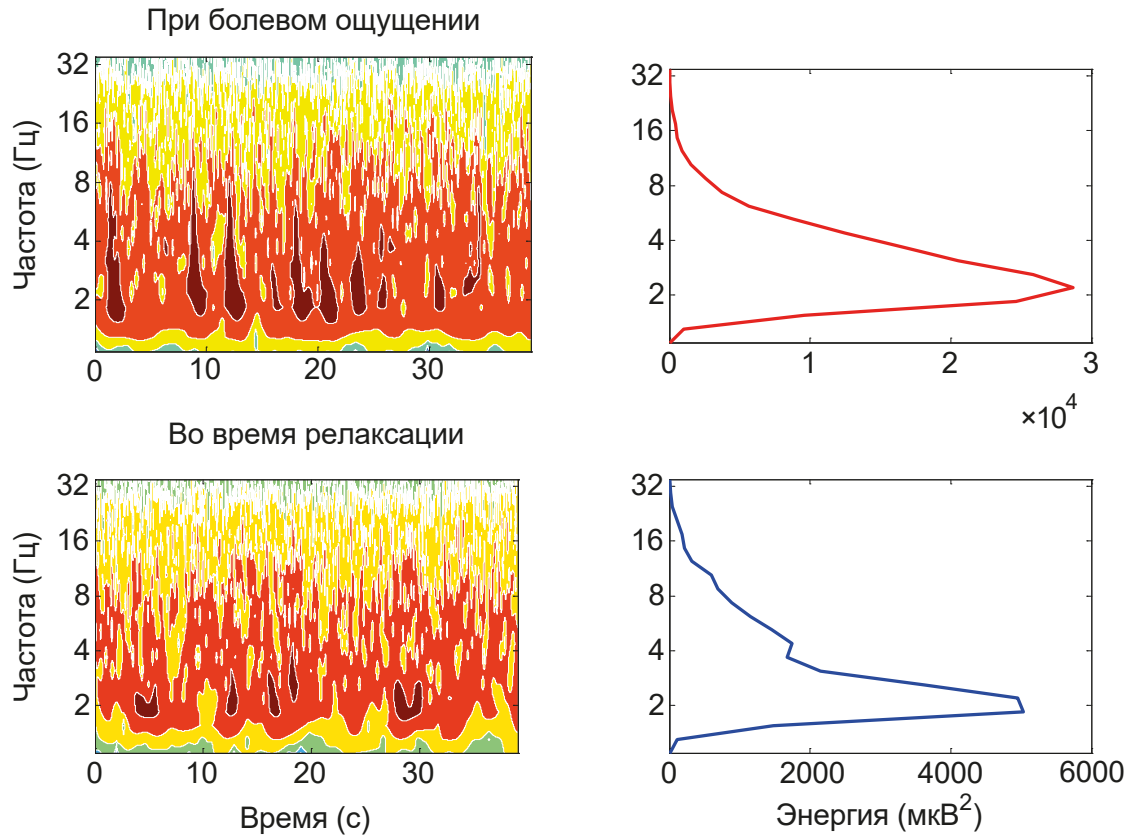

Puc. 3.4. Примеры распределений энергии $\left|W\left(a, t_{0}\right)\right|^{2}$ и глобальных вейвлетных спектров фрагментов ЭЭГ в различных состояниях человека с тревожнофобическими расстройствами из второй группы (отведение Qz)

яния по вейвлетному анализу ЭЭГ, так же как и по спектральному анализу, выявлено не было.

При ощущении психогенной боли пациент $A$ из второй группы с тревожно-фобическими расстройствами в глобальном вейвлетном спектре наблюдал один максимум на частотах тета-диапазона $E_{\max }=2,96 \times 10^{4}$, а во время релаксации это значение уменьшалось до величины $E_{\max }=0,51 \times 10^{4}$ (рис. 3.4).

Во время релаксации у всех пациентов второй группы глобальная энергия в затылочных отведениях уменьшалась более чем в 10 раз, т. е. тета-активность заметно снижалась, однако это не сопровождалось улучшением их психофизиологического состояния.

Таким образом, показано, что использование параметра $E_{\max }$ вейвлетного спектра позволяет достоверно различать состояния, связанные с эпилептическими разрядами, и состояния, им предшествующие, но не дает возможности надежно оценить эффективность психорелаксационной методики по устранению психогенной боли у пациентов с тревожно-фобическими расстройствами. 


\section{4. Мультифрактальные характеристики паттернов ЭЭГ человека при тревожно-фобических расстройствах}

Рассмотрим, позволяют ли мультифрактальные характеристики различать фрагменты ЭЭГ в исследуемых функциональных состояниях.

Усредненные (по соответствующим сегментам) мультифрактальные зависимости $h(q)$ и спектры сингулярностей $D(h)$ для различных функциональных состояний здорового человека (до болевой стимуляции, во время болевого воздействия и после него) показаны на рис. 3.5.

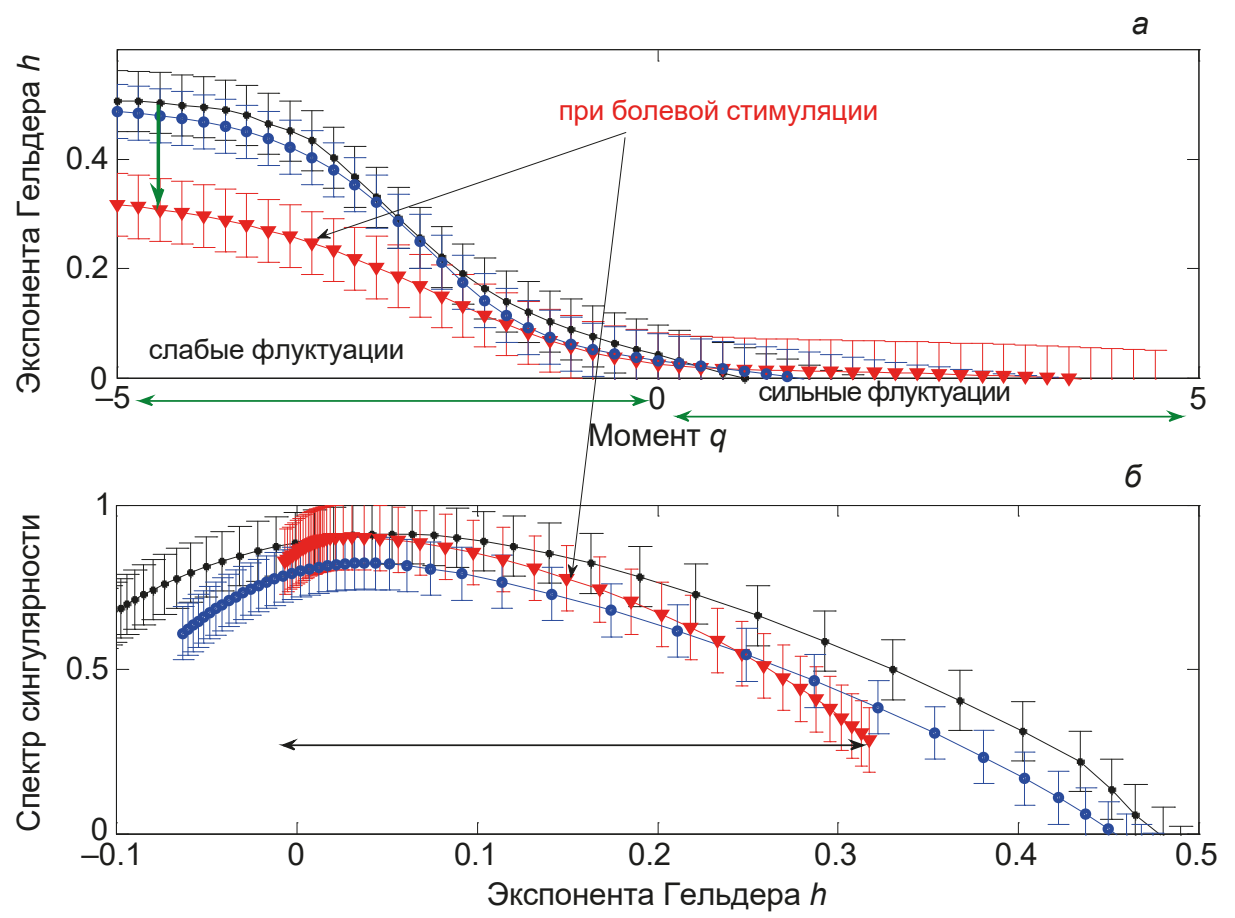

Puc. 3.5. Зависимости $h(q)$ и спектры сингулярностей для трех состояний здорового человека (отведение Qz): до болевой стимуляции кривые отмечены черным цветом; во время болевого воздействия - красным; во время релаксации - голубым

Во время болевой стимуляции наблюдается уменьшение мультифрактальных параметров: максимального значения экспоненты Гельдера до величины $h_{\max }=031 \pm 0,05$ и ширины спектра сингулярности до величины $\Delta h=0,35 \pm 0,06$, а во время психорелаксации происходит восстановление этих параметров практически до прежних значений (см. рис. 3.5). Во всех трех состояниях $h_{\max }<0,5$, т.е. спектр сингулярности соответствует антикоррелированной динамике последовательных значений ЭЭГ (когда за малым значением сигнала следует большое значение, и наоборот). Уменьшение величины $h_{\max }$ 

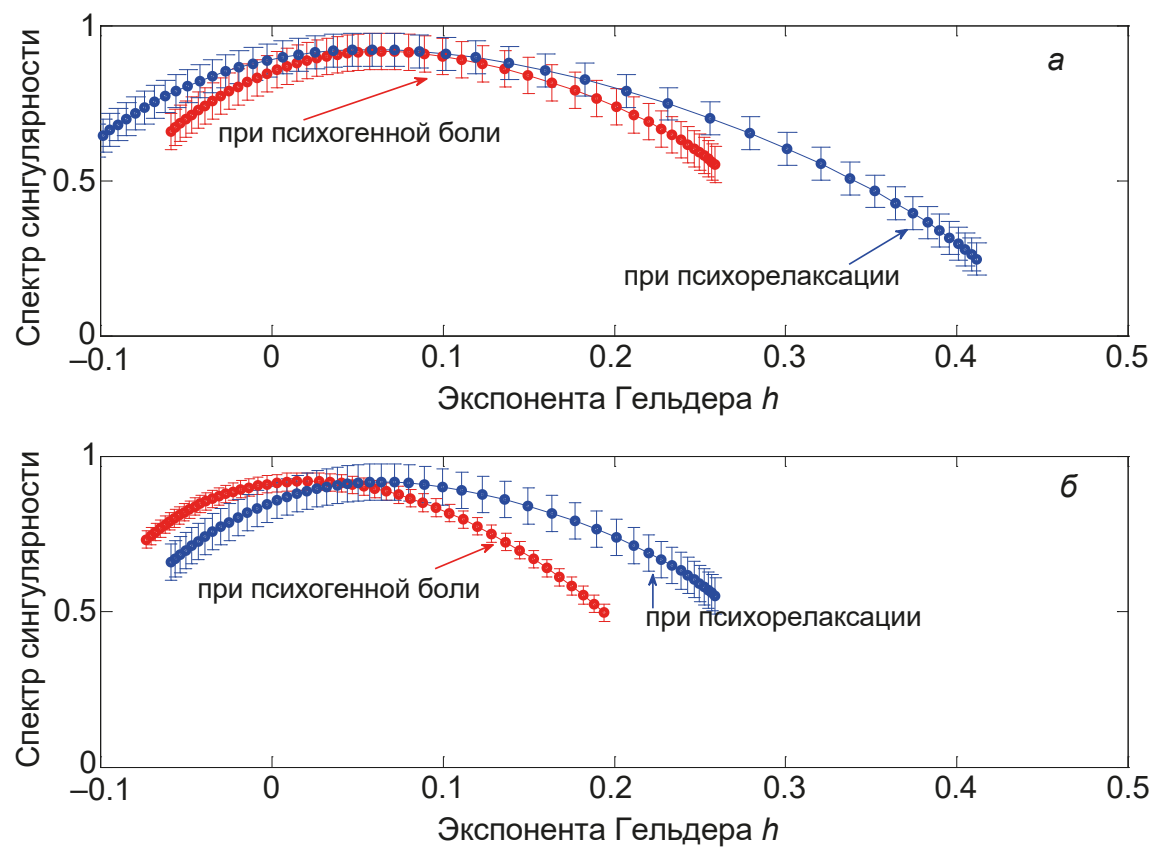

Puc. 3.6. Примеры спектров сингулярностей у пациентов с тревожно-фобическими расстройствами из первой группы: красным цветом - во время ощущения психогенной боли; голубым - во время релаксации

при болевой стимуляции свидетельствует о повышении степени антикоррелированности паттерна (сигнал становится менее гладким и более сингулярным), а последовательные значения ЭЭГ - более случайными.

Уменьшение ширины спектра сингулярности во время болевой стимуляции подтверждает снижение степени мультифрактальности сигнала и, следовательно, снижение степени его неоднородности. Это уменьшение происходит за счет сокращения вклада слабых флуктуаций (при $q<0, h>0$ ), в то время как при сильных флуктуациях (при $q>0$ ) сигнал становится монофрактальным (однородным по скейлинговым характеристикам), и спектр сингулярностей превращается в точку $(h=$ const). Подобная динамика изменений мультифрактальных параметров была характерна не менее чем для $90 \%$ лиц из каждой обследуемой группы, что позволило нам применить стандартную методику усреднения по паттернам всех тестируемых в данной группе [105].

Типичные усредненные (по соответствующим сегментам) спектры сингулярностей во время ощущения психогенной боли и во время релаксации у пациентов с тревожно-фобическими расстройствами из первой группы представлены на рис. 3.6. При ощущении психогенной боли пациентами этой группы ширина спектра сингулярностей оказалась меньше значений, полученных для здоровых лиц (рис. 3.5 и 3.6 - данные для одного и того же заты- 
39 \% первой группы лиц с тревожно-фообическими растройствами
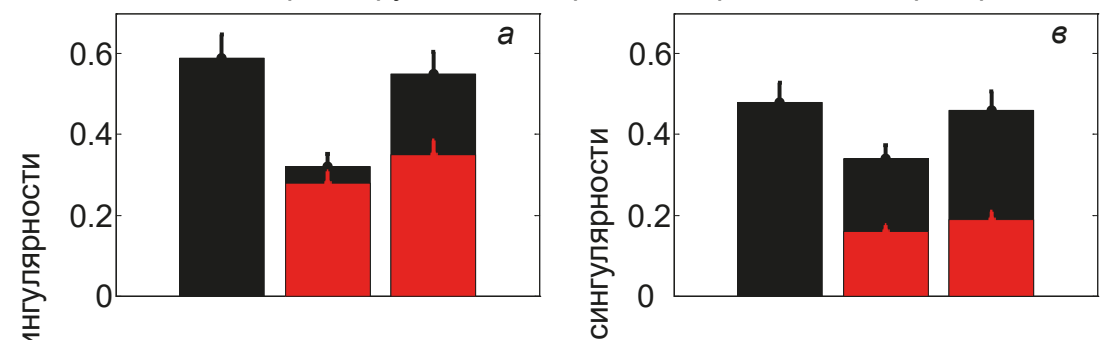

61 \% первой группы лиц с тревожно-фробическими растройствами
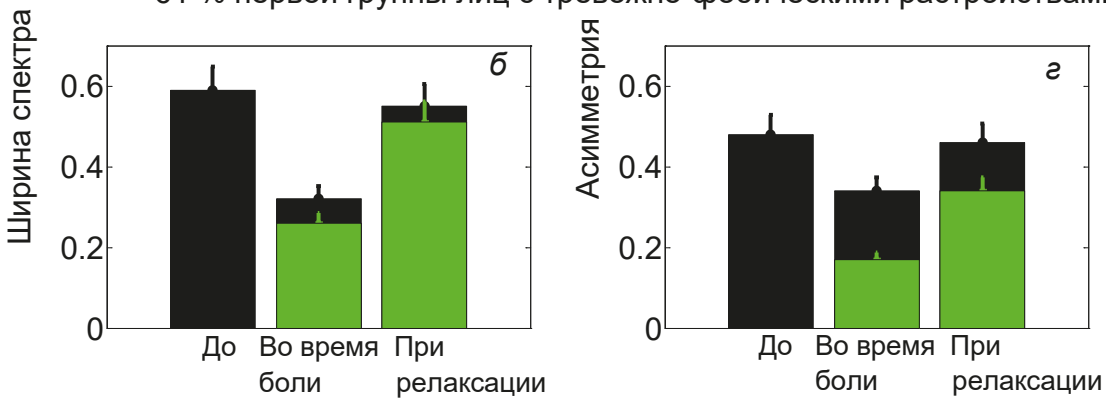

PUc. 3.7. Мультифрактальные параметры (ширина и асимметрия спектра сингулярности) во время ощущения психогенной боли у пациентов с тревожнофобическими расстройствами из первой группы: черный цвет соответствует значениям мультифрактальных параметров для здоровых испытуемых; красный и зеленый - для лиц с тревожно-фобическими расстройствами

лочного отведения Oz). Во время релаксации значение ширины спектра сингулярности в большей степени увеличивается для примера, представленного на рис. 3.6, $а$, чем на рис. 3.6, 6 .

Отметим, что, как и для паттернов ЭЭГ здоровых лиц, у пациентов первой группы максимальная величина экспоненты Гельдера $h_{\max }<0,5$, что означает, что спектр сингулярности также соответствует антикоррелированной динамике последовательных значений ЭЭГ. Однако значения экспонент Гельдера меньше для этой группы пациентов, чем для здоровых лиц. Следовательно, степень антикоррелированности последовательных значений ЭЭГ для лиц с тревожно-фобическими расстройствами больше, чем для здорового человека.

Сравнительные данные значений мультифрактальных параметров для здоровых лиц и лиц первой группы больных представлены на рис. 3.7. У $61 \%$ пациентов первой группы оба мультифрактальных параметра (ширина и асимметрия спектра сингулярности) значимо возрастали во время релаксации (рис. $3.7,6$, 2), то время как у $39 \%$ лиц эти параметры изменялись незначительно (рис. 3.7, a, в). Это совпадало с полным устранением болевого ощущения у $61 \%$ пациентов исследуемой группы. Таким образом, улучшение функционального состояния пациентов первой группы (устранение болевого 

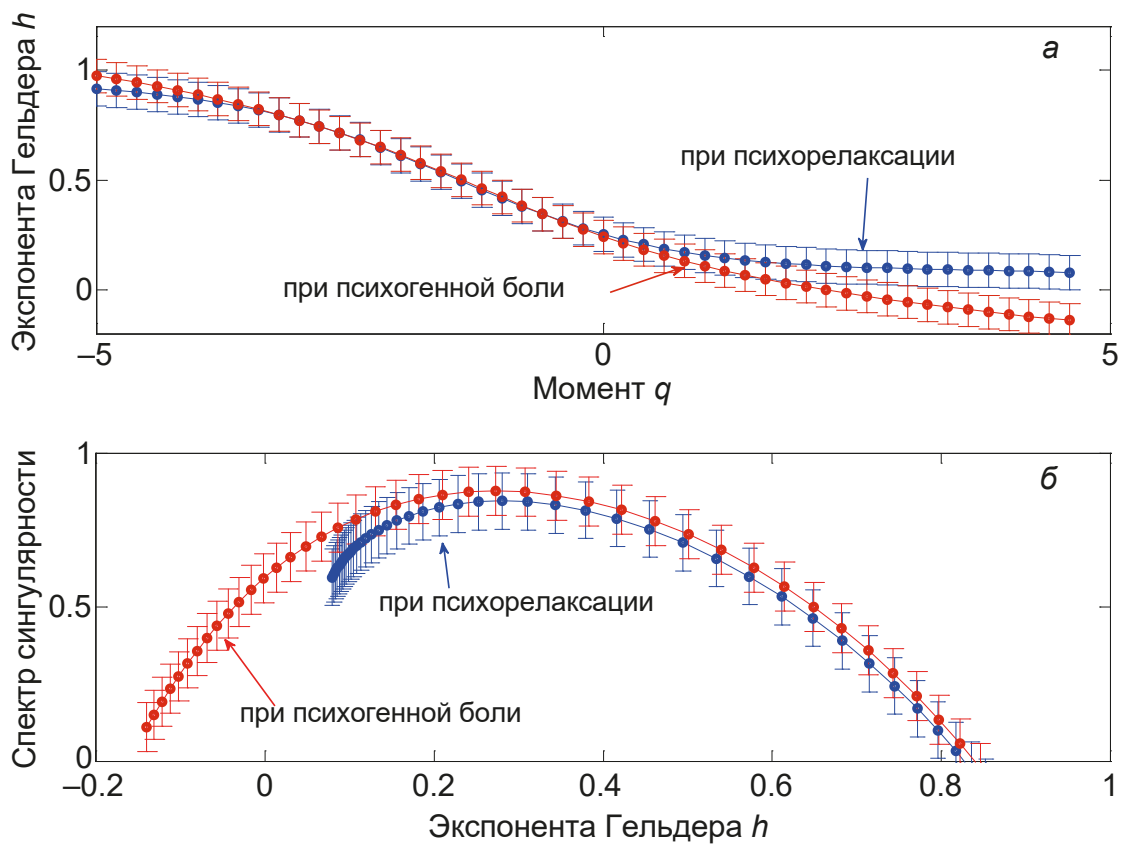

Puc. 3.8. Примеры зависимостей $h(q)$ и спектров сингулярностей у пациентов с тревожно-фобическими расстройствами из второй группы: красные кривые - во время ощущения психогенной боли; голубые - во время релаксации (данные для затылочного отведения Oz)

синдрома) соответствовало уменьшению степени антикоррелированности последовательных значений ЭЭГ в исследуемых отведениях.

Типичные примеры мультифрактальных зависимостей $h(q)$ и спектров сингулярностей у пациентов с тревожно-фобическими расстройствами из второй группы во время ощущения психогенной боли и во время релаксации представлены на рис. 3.8. Во время ощущения психогенной боли пациентом из второй группы максимальное значение экспоненты Гельдера и ширина спектра сингулярности значительно больше значений этих параметров, полученных для здорового человека $\left(h_{\max }=0,98 \pm 0,09, \Delta h=0,95 \pm 0,08\right)$. Следовательно, степень мультифрактальности последовательных значений ЭЭГ для этого пациента значительно превышает эту величину для здорового тестируемого. Спектр сингулярностей $(-0,15<h<0,82)$ во время болевого ощущения соответствует как коррелированной $(h>0,5)$, так и антикоррелированной $(h<0,5)$ динамике. Во время релаксации ширина спектра сингулярностей уменьшается за счет снижения вклада сильных флуктуаций (при $q>0$ и $h<0,25)$, при которых гельдеровские экспоненты остаются постоянными (см. рис. 3.8, а), а спектр вырождается в точку (см. рис. 3.8, б). Однако в целом степень мультифрактальности остается высокой, и спектр сингуляр- 
100 \% второй группы лиц с тревожно-фробическими растройствами
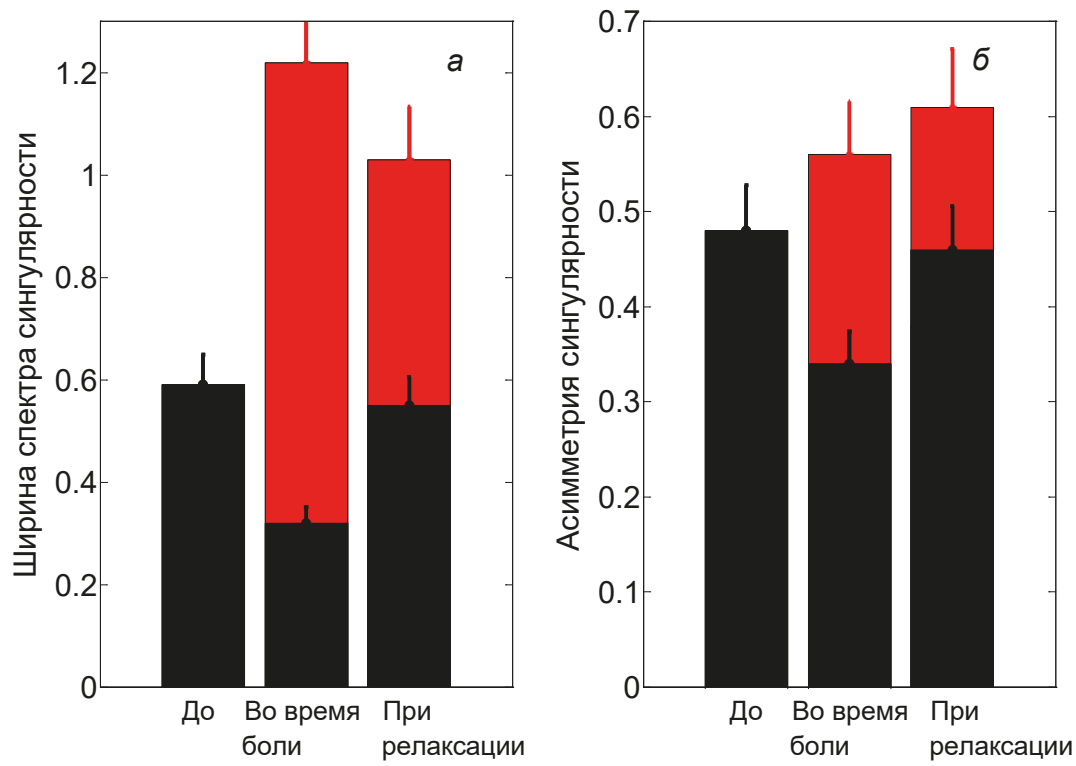

Puc. 3.9. Мультифрактальные параметры (ширина и асимметрия спектра сингулярности) у пациентов с тревожно-фобическими расстройствами из второй группы во время ощущения психогенной боли и релаксации (черный цвет - мультифрактальные параметры здоровых испытуемых; красный - лиц с тревожно-фобическими расстройствами)

ностей соответствует как коррелированной, так и антикоррелированной динамике. Асимметрия спектра сингулярности во время релаксации возрастает (см. рис. 3.8, б).

Во время ощущения психогенной боли мультифрактальные параметры (ширина и асимметрия спектра сингулярности) у всех пациентов второй группы превосходят значения этих параметров, полученных для здоровых лиц (рис. 3.9). Во время релаксации у пациентов анализируемой группы ширина спектра сингулярности уменьшалась, а асимметрия спектра сингулярности возрастала за счет смещения спектра в область положительных значений экспонент Гельдера, где основной вклад вносят слабые флуктуации. Однако значения мультифрактальных параметров по-прежнему превышали значения, характерные для паттернов ЭЭГ здорового человека. Это коррелировало с отсутствием устранения болевого ощущения при релаксации у $100 \%$ тестируемых больных. 


\section{5. Анализ возможности коррекции тревожно-фобических расстройств на основе вейвлетных и мультифрактальных характеристик паттернов ЭЭГ}

Обобщенная информация о средних значениях мультифрактального $(\Delta h)$ и энергетического $\left(E_{\max }\right)$ параметров для здоровых лиц и лиц с тревожно-фобическими расстройствами двух групп исследуемых пациентов, а также о трансформации цветовых ощущений и устранении болевого ощущения или отсутствии такого устранения у тестируемых лиц представлена в табл. 3.1. Данные таблицы показывают, что в первой группе лиц с тревожно-фобическими расстройствами устранение болевого ощущения при релаксации наблюдается у 61 \% пациентов группы и совпадает с трансформацией цветовых пятен к коротковолновому голубому цвету, а также коррелирует с возрастанием ширины спектра сингулярности до значений, характерных для здоровых лиц. В паттернах $39 \%$ тестируемых этой группы ширина спектра сингулярности возрастает незначительно во время релаксации, отсутствует трансформация цветовых пятен и болевое ощущение сохраняется.

Таблица 3.1. Сравнение средних значений мультифрактальных и энергетических параметров ( $\Delta h$ и $\left.E_{\max }\right)$ для здоровых лиц и лиц с тревожно-фобическими расстройствами (отведение Qz, усреднение по числу лиц в группе)

\begin{tabular}{|c|c|c|c|c|}
\hline Состояние & Цветовое ощущение & $E_{\max } \times 10^{4}$ & $\Delta h$ & $\begin{array}{c}\text { Устранение } \\
\text { болевого ощущения }\end{array}$ \\
\hline \multicolumn{5}{|c|}{ Здоровые лица (отведение Qz) } \\
\hline $\begin{array}{l}\text { До болевого } \\
\text { воздействия }\end{array}$ & & $2,3 \pm 0,3$ & $0,59 \pm 0,05$ & - \\
\hline Во время боли & Ахроматический серый & $9,6 \pm 0,9$ & $0,32 \pm 0,03$ & - \\
\hline $\begin{array}{l}\text { Во время } \\
\text { релаксации }\end{array}$ & Голубой или зеленый & $5,7 \pm 0,6$ & $0,55 \pm 0,05$ & $\begin{array}{c}\text { Да, у } 100 \% \\
\text { тестируемых }\end{array}$ \\
\hline \multicolumn{5}{|c|}{ Лица с тревожно-фобическими расстройствами из первой группы (отведение Qz) } \\
\hline Во время боли & Красный или желтый & $61,5 \pm 5,8$ & $0,28 \pm 0,03$ & \\
\hline $\begin{array}{l}\text { Во время } \\
\text { релаксации }\end{array}$ & Красный или желтый & $7,7 \pm 0,8$ & $0,35 \pm 0,03$ & $\begin{array}{c}\text { Нет, у } 39 \% \\
\text { тестируемых }\end{array}$ \\
\hline $\begin{array}{l}\text { Во время } \\
\text { релаксации }\end{array}$ & Голубой & $5,1 \pm 0,5$ & $0,52 \pm 0,06$ & $\begin{array}{c}\text { Да, у } 61 \% \\
\text { тестируемых }\end{array}$ \\
\hline \multicolumn{5}{|c|}{ Лица с тревожно-фобическими расстройствами из второй группы (отведение Qz) } \\
\hline Во время боли & $\begin{array}{c}\text { Ахроматический } \\
\text { черный }\end{array}$ & $4,5 \pm 0,3$ & $1,22 \pm 0,11$ & - \\
\hline $\begin{array}{l}\text { Во время } \\
\text { релаксации }\end{array}$ & $\begin{array}{c}\text { Черный, красный или } \\
\text { оранжевый }\end{array}$ & $0,62 \pm 0,05$ & $1,03 \pm 0,10$ & $\begin{array}{l}\text { Нет, у } 100 \% \\
\text { тестируемых }\end{array}$ \\
\hline
\end{tabular}


Во второй группе лиц с тревожно-фобическими расстройствами устранение болевого ощущения при релаксации не наблюдается у $100 \%$ пациентов группы даже после 20 повторяющихся сеансов применения психорелаксационной методики и обучения пациентов концентрировать свое внимание на болевых ощущениях и устанавливать связи между болевыми ощущениями, цветовыми образами и эмоциональным состоянием. При этом сохраняется коррелированная динамика $(h>0,5)$ последовательных значений ЭЭГ, а спектр сингулярности не приближается к спектру, характерному для здоровых лиц.

Таким образом, устранение болевых симптомов во время психорелаксации у лиц с тревожно-фобическими расстройствами характерно только для пациентов первой группы. При этом устранение боли сопровождается трансформацией цветовых пятен в сторону цветов, наблюдаемых здоровыми людьми, а также изменением значений мультифрактальных параметров в сторону значений, характерных для здоровых лиц. 